\title{
Impak persempadanan semula bahagian pilihan raya terhadap pola pengundian dalam pilihan raya umum ke-14 di kawasan DUN Kadok dan Melor, Kelantan
}

\author{
Mohd Nor Hafis Ahmad Pauzan ${ }^{1}$, Junaidi Awang Besar ${ }^{1}$, Hamzah Jusoh ${ }^{2}$ \\ ${ }^{1}$ Program Geografi, Pusat Kajian Pembangunan, Sosial dan Persekitaran, \\ Fakulti Sains Sosial dan Kemanusiaan, Universiti Kebangsaan Malaysia \\ ${ }^{2}$ Program Sains Pembangunan, Pusat Kajian Pembangunan, Sosial dan Persekitaran, \\ Fakulti Sains Sosial dan Kemanusiaan, Universiti Kebangsaan Malaysia \\ Correspondence: Junaidi Awang Besar (email: jab@ukm.edu.my)
}

Received: 05 May 2020; Accepted: 27 May 2021; Published: 29 May 2021

\begin{abstract}
Abstrak
Persempadanan semula merupakan salah satu elemen penting dalam sistem pilihan raya bagi sebuah negara yang mengamalkan prinsip demokrasi. Persempadanan merujuk kepada garisan kawasan yang menentukan pembahagian kuasa pentadbiran dan pemetaan. Persempadanan sesuatu kawasan adalah berbeza bergantung kepada keperluan sama ada di bawah bidang kuasa negeri, pihak berkuasa tempatan dan juga sempadan pilihan raya. Justeru adalah menjadi tujuan penulisan artikel ini untuk menganalisis impak persempadanan semula bahagian pilihan raya terhadap pola pengundian di kawasan DUN Kadok dan Melor, Kelantan. Berdasarkan kepada pemerhatian di lapangan, sesi temu bual, 'scoresheet' keputusan pilihan raya, kajian perpustakaan dan peratusan bantahan ke atas pemilih di kawasan terlibat, didapati bahawa wujudnya ketidakseimbangan dari segi populasi pemilih di kedua-dua kawasan tersebut. Pendefinasian yang sesuai dalam aspek ketidakseimbangan ini dikategorikan sebagai 'malapportionment'. Ianya juga jelas menunjukkan bahawa prinsip 'one man one vote, one vote one value' diketepikan sama sekali demi mengukuhkan kuasa geopolitik sesuatu parti. Justeru itu, artikel ini mengupas lebih lanjut mengenai kesan pelaksanaan persempadanan semula terhadap pola pengundian di kawasan DUN Kadok dan Salor, Kelantan pada pilihan raya umum yang ke-14.
\end{abstract}

Katakunci: Geopolitik, malapportionment, persempadanan semula, persempadanan, pilihan raya, pola pengundian. 


\title{
Impact of electoral redistricting on 14th general election pattern in Kadok and Melor constituencies, Kelantan
}

\begin{abstract}
Redelineation is one of the important elements of the electoral system of a country that practices the principles of democracy. Boundaries refer to area lines that determine the distribution of administrative power and mapping. The boundaries of a constituency are different depending on the needs of the state, local authorities and electoral boundaries. Thus, the purpose of this article is to analyze the impact of electoral redistricting on voting patterns in Kadok and Melor constituencies, Kelantan. Based on the observations, polling sessions, 'scoresheet' of election results, library studies and the percentage of votes against voters in the constituencies, it was found that there was an imbalance in the voting population in both areas. The appropriate definition of this imbalance is categorized as 'Malapportionment'. It also clearly shows that the principle of 'one man one vote, one vote one value' is completely ignored in order to strengthen a party's geopolitical power. Therefore, this article will discuss further the effects of the re-enactment of the electoral roll on the Kadok and Salor, Kelantan constituencies in the 14th general election.
\end{abstract}

Keywords: Geopolitics, malapportionment, redelineation, boundaries, elections, voting pattern.

\section{Pengenalan}

Urusan Kajian Semula Persempadanan Bahagian-Bahagian Pilihan Raya Persekutuan dan Negeri bagi Negeri-Negeri Tanah Melayu di Semenanjung Malaysia telah diluluskan dalam Dewan Rakyat pada 28 Mac 2018 dan seterusnya digunapakai bagi Pilihan Raya Umum ke14, 2018. Persempadanan ini merupakan salah satu perkara yang penting dalam proses pilihan raya. Suruhanjaya Pilihan Raya Malaysia (SPR) yang ditubuhkan selaras dengan peruntukan Perkara 114, Perlembagaan Persekutuan telah diberi mandat sepunuhnya dalam melaksanakan kajian semula persempadanan. Ianya juga selaras dengan Perkara 113, Perlembagaan Persekutuan yang mana kajian semula persempadanan kawasan pilihan raya parlimen dan negeri perlu dilakukan apabila mencapai syarat yang telah ditetapkan. Sempadan adalah merujuk kepada garisan kawasan yang menentukan pembahagian kuasa pentadbiran dan pemetaan. Bagi menjalankan urusan pentadbiran dalam sesuatu bahagian pilihan raya, elemen persempadanan perlu dilakukan dengan mengambilkira prinsip-prinsip utama persempadanan sepertimana yang telah digariskan dalam Perlembagaan Persekutuan di bahagian Jadual Ketiga Belas. Persempadanan penting agar kepadatan pemilih di sesuatu kawasan dapat dikawal dengan menghasilkan jumlah yang hampir seragam untuk sesuatu kawasan. Ianya telah dilakukan di beberapa buah negara yang mana corak atau prinsip yang digunapakai mungkin berbeza jika dibandingkan dengan Malaysia. Walau bagaimanapun, asas kepada satu pilihan raya yang demokratik dan adil, populasi dalam bahagian pilihan raya tersebut perlulah seimbang atau sama. Perlaksanaan persempadanan dalam sesebuah bahagian pilihan raya akan memberi kesan sama ada dari segi populasi kaum, pola pengundian, populariti dan sebagainya. Oleh itu, artikel ini akan membahaskan secara terperinci kesan persempadanan semula ke atas trend pengundian di kawasan DUN Kadok dan Salor, Kelantan pada pilihan raya umum yang ke-14. 


\section{Persempadanan semula dan pilihan raya di Malaysia}

Sebagai sebuah negara yang mempraktikkan konsep demokrasi berparlimen, asas kepada sistem pilihan raya perlu lebih adil dan demokratik serta ditadbir urus oleh sebuah badan yang diberi mandat sepenuhnya dalam menguruskan hal-hal urusan pilihan raya. Sepertimana yang diperuntukan dibawah Perkara 114, Perlembagaan Perksekutuan, Suruhanjaya Pilihan Raya (SPR) telah ditubuhkan dan tertakluk kepada peruntukan undang-undang, SPR diberi mandat untuk menguruskan pilihan raya, menyemak dan menyediakan daftar pemilihan bagi pilihan raya serta, mengkaji semula pembahagian Persekutuan dan Negeri-Negeri sekiranya difikirkan perlu dan telah mencapai tempoh yang telah ditetapkan. Semenjak kemerdekaan, urusan Kajian Semula Persempadanan Bahagian-Bahagian Pilihan Raya Persekutuan dan Negeri bagi NegeriNegeri Tanah Melayu telah dilakukan sebanyak 5 kali iaitu pada tahun 1958, 1974, 1984, 1994 dan 2003. Persempadanan ini dibuat dengan mengambilkira pertambahan populasi penduduk di setiap negeri, perkembangan sosioekonomi semasa yang sedang pesat membangun serta peningkatan kesejahteraan rakyat.

Di Malaysia, konsep pembentukan sebuah bahagian pilihan raya dipecahkan kepada 4 struktur utama iaitu lokaliti, Daerah Mengundi (DM), Dewan Undangan Negeri (DUN) dan Parlimen. Struktur ini ditentukan melalui sempadan yang dibuat oleh SPR dengan mengambilkira kedudukan sempadan jajahan dibawah bidang kuasa negeri dan pihak berkuasa tempatan. Sempadan ini penting supaya urusan pendaftaran pemilih dapat ditentukan berdasarkan kepada kod-kod lokaliti yang telah ditetapkan. Lokaliti merujuk kepada kepada satu-satu kawasan kediaman atau perumahan dan digabungkan dengan beberapa lokaliti yang berhampiran bagi membentuk satu daerah mengundi. Sebagai pra syarat yang telah ditetapkan oleh SPR, jumlah pemilih dalam satu-satu lokaliti tidak terhad. Walau bagaimanapun, gabungan satu-satu lokaliti dalam membentuk satu daerah mengundi adalah tidak lebih dari 3,700 pemilih dan tertakluk kepada keadaan muka bumi dan topografi, tahap pembangunan, kemudahan asas dan infrastruktur dan sebagainya. Pada pilihan raya umum atau pilihan raya kecil, satu pusat mengundi akan diwujudkan di setiap daerah mengundi bagi memudahkan pemilih di daerah tersebut menunaikan tanggungjawab sebagai pengundi. Selanjutnya, daerahdaerah mengundi ini akan digabungkan untuk mewujudkan satu DUN, dan DUN digabungkan untuk membentuk satu parlimen menjadikan satu bahagian pilihan raya.

Elemen persempadanan berkait rapat dengan urusan perjalanan pilihan raya dalam menentukan had kuasa/sempadan pentadbiran bagi seseorang wakil rakyat dan juga dalam urusan pendaftaran pemilih. Terdapat 4 peringkat utama proses persempadanan yang merangkumi urusan kajian, cadangan syor pertama kajian, cadangan syor kedua kajian, dan yang terakhir adalah mendapat kelulusan di peringkat Dewan Rakyat. SPR akan menjalankan kajian berlandaskan kepada prinsp-prinsip yang telah ditetapkan dibawah perlembagaan. Asas kepada sesuatu persempadanan adalah berdasarkan kepada sempadan nyata sama ada secara semula jadi seperti sungai, tali air, bukit bukau dan sebagainya atau secara artificial seperti jalan-jalan raya, jalan keretapi, talian utama elektrik dan sebagainya. Penentuan garisan sempadan ini juga mengambil kira kedudukan muka bumi, topografi, kemudahan asas dan infrastruktur, dan tahap-tahap pembangunan. Sebelum sesuatu sempadan pilihan raya dilakukan perkara asas dan paling utama yang menjadi keutamaan SPR adalah kemudahan premis untuk dijadikan pusat mengundi dan juga akses pergerakan pengundi kelak.

Setelah selesainya urusan kajian dan penentuan sempadan, satu syor akan dipamerkan bagi mendapatkan pandangan awam melalui rayuan yang dikemukakan, bantahan, dan proses siasatan tempatan. Mengambilkira cadangan dan pandangan melalui 3 kategori bantahan iaitu kerajaan negeri, pihak berkuasa tempatan dan 100 pengundi yang terkesan dengan cadangan proses persempadanan, SPR akan mencadangkan syor 2 dan melalui proses sepertimana di syor yang pertama. Dalam urusan siasatan tempatan, pihak SPR akan mengadakan sesi pendengaran 
awam dimana pihak-pihak yang berkepentingan melalui 3 kategori utama pembantah seperti mana yang dinyatakan tersebut diberi peluang untuk mengemukakan hujah, pandangan dan bantahan ke atas syor yang dibuat oleh pihak SPR. Kesemua syor dan cadangan persempadanan adalah bagi memastikan setiap pemilih mempunyai akses, kemudahan untuk melaksanakan tanggungjawab sebagai pengundi samada pada pilihan raya umum yang diadakan setiap 5 tahun mahupun pilihan raya kecil bila berlakunya kekosongan.

\section{Tinjauan literatur}

Beberapa kajian telah dilaksanakan berhubung dengan urusan persempadanan pilihan raya. Di luar negara misalnya, melalui kajian yang dijalankan, terdapat cadangan penubuhan satu standard piawaian antarabangsa dalam sistem pilihan raya terutamanya berkaitan proses persempadanan oleh pertubuhan kerajaan dan bukan kerajaan. Antara pertubuhan yang terlibat termasuk Organization of Security Co-operation in Europe (OSCE), Suruhanjaya Eropah untuk Demokrasi Melalui Undang-undang, Sekretariat Komanwel, dan Electoral Institute of Southern Africa (EISA). Dalam kajian tersebut, ianya menggariskan 5 prinsip utama yang perlu diambilkira dalam urusan persempadanan antaranya Impartially (tidak berat sebelah, adil dan saksama), Equality (kesamarataan), Representativeness (perwakilan), Non-discrimination (tidak wujud diskriminasi), dan Transparency (telus) (Glassner, 1993). Bagi Malaysia yang mengamalkan sistem pilihan raya 'First Past the Post' (FPTP), akan membuka ruang dan peluang dalam memanipulasi urusan persempadanan dan memberi kesan pada pilihan raya.

Flaherty dan Crumplin (1992) menjelaskan bahawa kepadatan dan perubahan sempadan bahagian pilihan raya boleh dibuat dengan baik dan adil berdasarkan pengukuran alternatif yang melibatkan kajian dan kerjasama pihak berkuasa tempatan dan suruhan jaya pilihan raya di sesebuah negara. Corak persempadanan juga berkait rapat dengan faktor sentimen perkauman dalam meraih sokongan kaum tertentu. Ini dibuktikan melalui kajian Ismail (1979) yang menyatakan secara jelas hubung kait antara proses persempadanan semula dengan pengaruh politik kepartian Melayu dalam pilihan raya.

Lim (2003) dalam kajiannya mendapati proses persempadanan yang telah dilakukan membantu UMNO untuk terus mengukuhkan kuasa dalam parlimen. Konsep gerimander juga banyak memberi kesan ke atas perubahan kaum dalam satu-satu kawasan terutamanya kaum melayu. Ini dibuktikan dengan kajian Rosmadi (2006 \& 2015) dan Rosmadi et al. (2013) mengaitkan proses persempadanan berbentuk gerimander yang dilakukan oleh SPR telah memberi kelebihan kepada parti pemerintah di DUN Kedah. Junaidi (2008) menyatakan persempadanan yang dilakukan pada tahun 2003 wujudnya ketidakseimbangan di kawasan DUN Kajang dan Bangi melalui proses gerimander. Brown (2005) menjelaskan bahawa indikator etnik yang menjadi petunjuk kepada persempadanan semula bahagian pilihan raya pada tahun 2003 dan pola pengundian dalam lima pilihan raya umum pada tahun 1986 hingga 2004. Sothi (1992) menghujahkan bahawa parti politik yang mengemudi sesuatu kerajaan dapat menetapkan persempadanan semula kawasan pilihan raya memberi kelebihan kepada parti tersebut dari segi peningkatan kerusi pilihan raya mahupun kewujudan kawasan pilihan raya yang boleh memberi kelebihan kepada parti politik tersebut.

Syed Azman (2003) menghuraikan bahawa persempadanan semula kawasan pilihan raya negeri-negeri Tanah Melayu 2003 adalah berat sebelah dan cenderung kepada parti pemerintah berikutnya melanggar prinsip persempadanan kawasan pilihan raya yang termaktub dalam Perlembagaan Persekutuan. Lim (2003) dalam kajiannya berhubung antara persempadanan bahagian pilhan raya dengan pengekalan pengaruh UMNO mendapati sepanjang proses persempadanan yang dilakukan terus memberi kelebihan kepada UMNO di mana pewakilan parti ini dalam Parlimen kerap melangkaui 2/3. Norelfaedyla (2005) dalam 
kajian persempadanan semula kawasan pilihan raya DUN Kajang 2003 mendapati bahawa persempadanan semula tersebut telah menghasilkan banyak perubahan kepada pola pengundian di kawasan tersebut.

Ong (2005) menjelaskan bahawa persempadanan semula kawasan pilihan raya di Kedah tidak menurut prinsip persempadanan yang mengambil kira sempadan pentadbiran pejabat tanah negeri, keseimbangan demografi dan nisbah pengundi antara bandar dan luar bandar. Fryer dan Holden (2011) menjelaskan bahawa pengukuran kepadatan sesuatu kawasan pilihan raya adalah berdasarkan kepada tiga petunjuk iaitu demografi pengundi, pembahagian kluster yang efisien, skala bervarian, kepadatan penduduk dan jumlah daerah pengundian yang ada di sesuatu kawasan pilihan raya.

Junaidi et al. (2012a \& 2012b) menghujahkan bahawa persempadanan semula bahagian pilihan raya 2003 menghasilkan perubahan bilangan pengundi secara keseluruhan, perubahan bilangan pengundi berdasarkan etnik, perubahan lokasi dan pertambahan serta pengurangan daerah mengundi, pertambahan kerusi DUN, perubahan lokasi DUN dalam kawasan Parlimen dan menghasilkan impak terhadap keputusan pilihan raya. Rosmadi et al. (2013a) dalam analisis georeruang sistem maklumat geografi pengukuran indeks kepadatan DUN yang dikaitkan dengan impak gerimander menunjukkan 16 DUN di Kedah telah berlaku gerimander dengan bacaan indeks kepadatan yang rendah, iaitu antara 0.1 sehingga 0.5 .

SUARAM (2013) menjelaskan bahawa persempadanan kawasan pilihan raya Malaysia sehingga tahun 2013 masih perlu ditambahbaik dari sudut formasi dan tatacara serta kuasa pihak yang terbabit dengan urusan persempadanan berkaitan agar ianya lebih saksama, mengikut prinsip Perlembagaan Persekutuan dan boleh diyakini oleh semua pihak. Sezali (2013) mendapati adanya amalan gerimender dengan purata indeks persempadanan 0.7116, iaitu pada kadar amalan gerimander yang rendah. Zulkifli (2013) menghuraikan pada tahun 2003, BN telah mengamalkan 'gerrymandering' dengan mengarahkan SPR mempersempadankan semula parlimen.

Lunday (2014) menjelaskan bahawa mereka mempertimbangkan beberapa metrik untuk mengukur bentuk daerah politik dengan kehadiran ciri-ciri geometri yang tidak diingini seperti pemanjangan, lekukan, dan pemisahan, yang masing-masing merupakan ciri khas gerrymandering mengikut Taylor (1973). Hazeeq (2015) menjelaskan bahawa persempadanan semula kawasan pilihan raya Malaysia yang sepatutnya perlu dibuatkan oleh SPR pada tahun 2011 perlu dilaksanakan secepat mungkin untuk mewujudkan peta kawasan sempadan yang bersesuaian dengan penambahan jumlah pemilih serta pertumbuhan kawasan perumahan dan sebaran perbandaran yang semakin meluas. Kajian oleh Fadilah (2015) menghuraikan bahawa petunjuk kaum menjadi salah satu perimeter penting dalam menentukan persempadanan kawasan pilihan raya.

Junaidi, Mohd Faidz dan Novel (2015) dalam kajian kesan persempadanan semula kawasan pilihan raya DUN Sarawak mendapati bahawa persempadanan semula kawasan pilihan raya telah mengubah landskap sosioekonomi dan sosiopolitik di bumi kenyalang ini. Zin (2016) menyatakan persempadanan semula bahagian pilihan raya Malaysia 2016 sangat penting kerana suasana politik pada masa kini yang menarik. Leib dan Quinton (2016) menjelaskan bahawa bidang kajian geografi pilihan raya terutamanya mengenai persempadanan semula bahagian pilihan raya semakin diberi penekanan sejak tahun 1990 kerana semua pihak terutamanya pengundi dan pengkaji politik pilihan raya peka terhadap pentingnya pembahagian kawasan pilihan raya yang adil dan tidak berat sebelah untuk memastikan semua pihak berpuas hati dengan pembahagian kawasan dan keputusan pilihan raya kelak.

Wan Mazlina et al. (2017) mendapati bahawa pengukuran elemen ruangan yang melibatkan indeks kepadatan khususnya membuktikan penggunaan geospatial lebih efisien dipraktikkan dalam sistem demokrasi moden kini. Junaidi et al. (2017a) menghuraikan bahawa 
persempadanan semula kawasan pilihan raya memberi impak kepada komposisi DUN dalam sesebuah Parlimen, jumlah pengundi, pertukaran nama, komposisi kaum, lokasi Daerah Mengundi, saiz km persegi dan dari segi unjuran jangkaan keputusan pilihan raya.

Junaidi et al. (2017b) menghuraikan bahawa responden tahu berkenaan impak perubahan sempadan yang akan dijalankan pada tahun 2016 ini terjadi disebabkan melibatkan hak dan kepentingan mereka. Ding dan Junaidi (2018) menghuraikan bahawa hasil daripada kajian kesan persempadanan semula terhadap persekitaran fizikal, kesan kepada persekitaran sosial, kesan terhadap persekitaran ekonomi dan kesan terhadap persekitatan politik menunjukkan bahawa perbezaan dan persepsi yang jelas dimana responden mempunyai tahap penerimaan yang berbeza. Justeru, dapatan kajian ini penting untuk dijadikan petunjuk oleh pihak berkenaan untuk sama ada mengekalkan sokongan ataupun mengembalikan sokongan pengundi kepada pihak berkenaan menjelang pilihan raya umum akan datang.

\section{Metod dan kawasan kajian}

Sumber data kajian adalah berasaskan kepada data primer dan data sekunder. Data primer diperoleh melalui pemerhatian di lapangan yang terlibat sepenuhnya dengan persempadanan, manakala data yang diperoleh melalui sumber sekunder adalah seperti keputusan pilihan raya (scoresheet) yang memperincikan secara jelas bilangan dan undian pemilih berdasarkan kepada daerah mengundi yang terlibat, Dalam artikel ini, DUN Kadok dan Salor (Kelantan) dipilih sebagai kajian kes bagi melihat secara keseluruhan kesan persempadanan dalam mempengaruhi pola pengundian. Kedua DUN dipilih berdasarkan kepada keluasan DUN, jumlah populasi yang hampir sama dan terletak dalam satu jajahan yang sama iaitu di bawah jajahan Kota Bharu, Kelantan. Proses persempadanan yang telah ditetapkan secara absah oleh SPR bagi negeri Kelantan merangkumi beberapa bahagian pilihan raya dan DUN Kadok serta DUN Salor tidak terkecuali dari proses tersebut. Kesan daripada persempadanan ini berlakunya perubahan kedudukan dan jumlah pemilih di beberapa daerah mengundi. Bagi melengkapkan kajian ini juga, responden dipilih berdasarkan kepada nama-nama orang yang dibantah oleh mana-mana orang yang namanya berada lama bahagian pilihan raya tersebut selaras dengan peraturan yang terkandung di bawah Paraturan-Peraturan Pilihan Raya (Pendaftaran Pemilih 2002). Bantahan ini wujud akibat daripada pemilih-pemilih yang tidak bersetuju dengan proses persempadanan semula, dan mengambil langkah menukar alamat daftar pemilih untuk terus kekal dalam bahagian pilihan rayanya.

Secara umumnya, Negeri Kelantan merupakan antara 3 negeri yang terletak di pantai timur dan terletak di utara Semenanjung Malaysia. Majoriti penduduk di negeri Kelantan adalah terdiri daripada kaum Melayu Bumiputera seramai 93.13\%, diikuti kaum Cina $3.11 \%$, $0.27 \%$ kaum India dan $0.62 \%$ lain-lain kaum minoriti. Negeri ini terdiri daripada 10 jajahan utama dan 1 jajahan kecil yang terletak di Lojing, Kelantan. Dalam urusan pilihan raya, terdapat 14 bahagian pilihan raya (parlimen) dan 45 kerusi DUN. Bagi jajahan Kota Bharu, terdapat 4 parlimen dan 12 DUN antaranya ialah Parlimen P.020 Pengkalan Chepa, P.021 Kota Bharu, P.024 Kubang Kerian dan P.026 Ketereh (SPR, 2003; 2018). Merujuk kepada kawasan kajian, kedudukan DUN Kadok adalah di bawah Parlimen Ketereh, manakala DUN Salor di Parlimen Kubang Kerian.

Perlimen P.026 Ketereh mempunyai 3 DUN, iaitu N.023 Melor, N.024 Kadok dan N.025 Kok Lanas (Rajah 1). Dari sudut kuasa pentadbiran, Parlimen Ketereh terletak di bawah bidang kuasa Majlis Daerah Ketereh hasil penyusunan semula Penguasa-Penguasa Tempatan di Kelantan di bawah Akta 171, Akta Kerajaan Tempatan pada 1 Januari 1979. Dengan keluasan 155.90 km persegi, ia meliputi keseluruhan Daerah Ketereh, Daerah Peringat, Daerah Kadok, Mukim Salor (Daerah Salor), Mukim Pendek (Daerah Pendek) dan Mukim Badak Mati (Daerah Banggu). Sehinggalah pada 9 September 2004, Parlimen Ketereh diwartakan kawasan 
baru seluas $49.04 \mathrm{~km}$ persegi yang merangkumi seluruh Daerah Beta, Daerah Salor, Mukim Lembu dan sebahagian Mukim Tiong (dalam Daerah Pendek) telah diluluskan dan menjadikan jumlah keluasan terbaru ialah seluas $204.94 \mathrm{~km}$ persegi. Berdasarkan kepada data yang dikeluarkan oleh SPR, jumlah pemilih berdaftar di parlimen Ketereh ialah seramai 62,217 pada PRU ke-13 dan 56,322 pada PRU ke-14, manakala jumlah pemilih di peringkat DUN Kadok pada PRU ke-13 ialah seramai 17,107 orang dan 16,583 orang pada PRU ke-14.

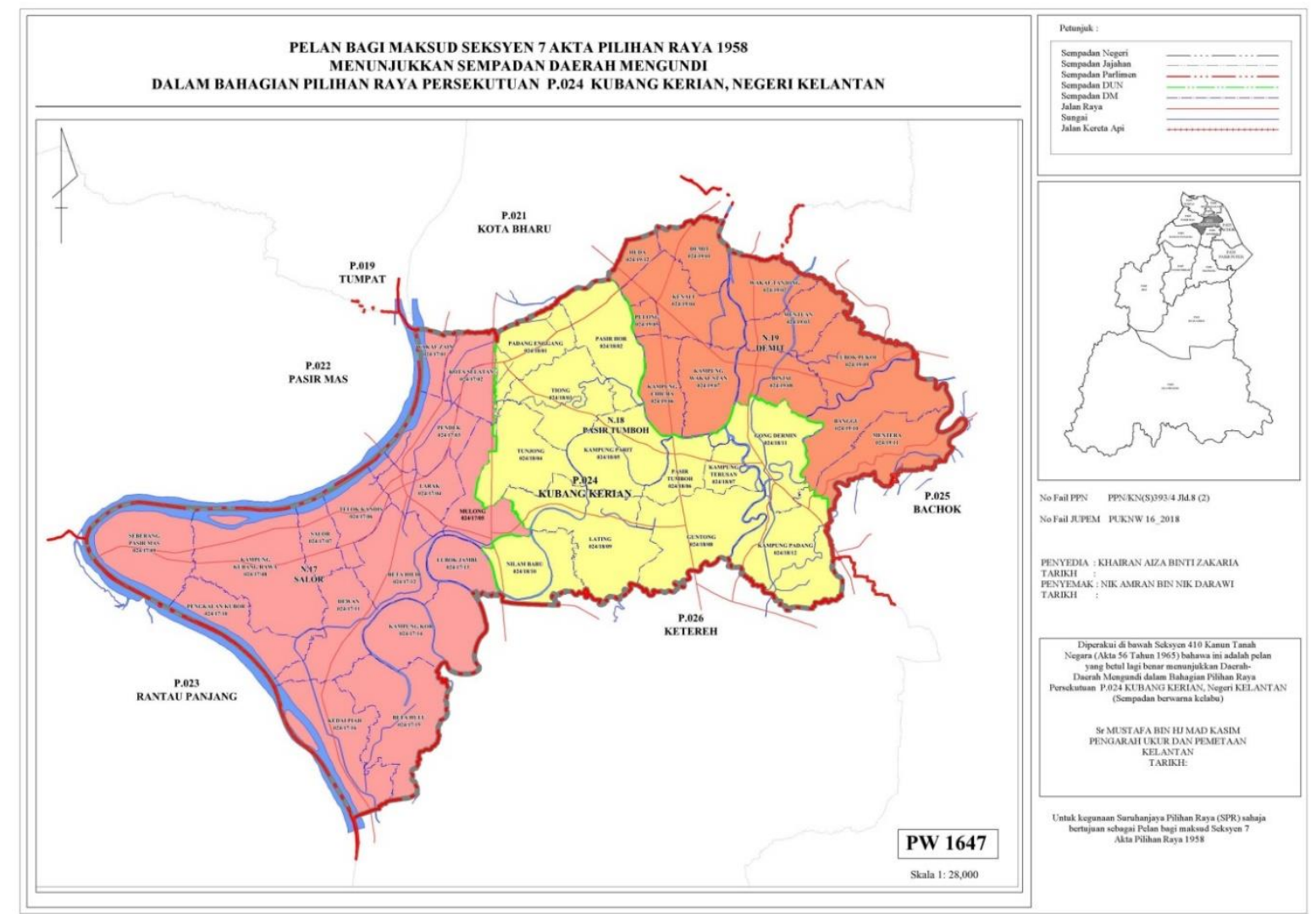

Sumber: SPR (2018)

Rajah 1. Peta kawasan pilihan raya Parlimen Kubang Kerian dan DUN Salor di Negeri Kelantan

DUN Salor terletak di bawah Parlimen P.024 Kubang Kerian yang mana kedudukannya berhampiran dengan Bandar Kota Bharu (Rajah 2). Walaupun di bawah satu jajahan yang sama sepertimana Parlimen Ketereh, iaitu di bawah jajahan Kota Bharu, urusan pentadbiran adalah di bawah Majlis Perbandaran Kota Bharu selaku pihak berkuasa tempatan. Kawasan Kubang Kerian boleh dikatakan sebagai bandar Kota Bharu kedua yang mana, dari segi kemudahan infrastruktur dan tahap pembangunan adalah jauh lebih maju jika dibandingkan dengan parlimen Ketereh. Kedudukan DUN Salor pada asasnya adalah dibawah tadbir urus Majlis Daerah Ketereh sepertimana diwartakan di bawah Akta Kerajaan Tempatan. Jumlah pemilih yang berdaftar DUN Salor bagi PRU ke-13 dan 14 ialah masing-masing 20,056 orang dan 27,164 orang 


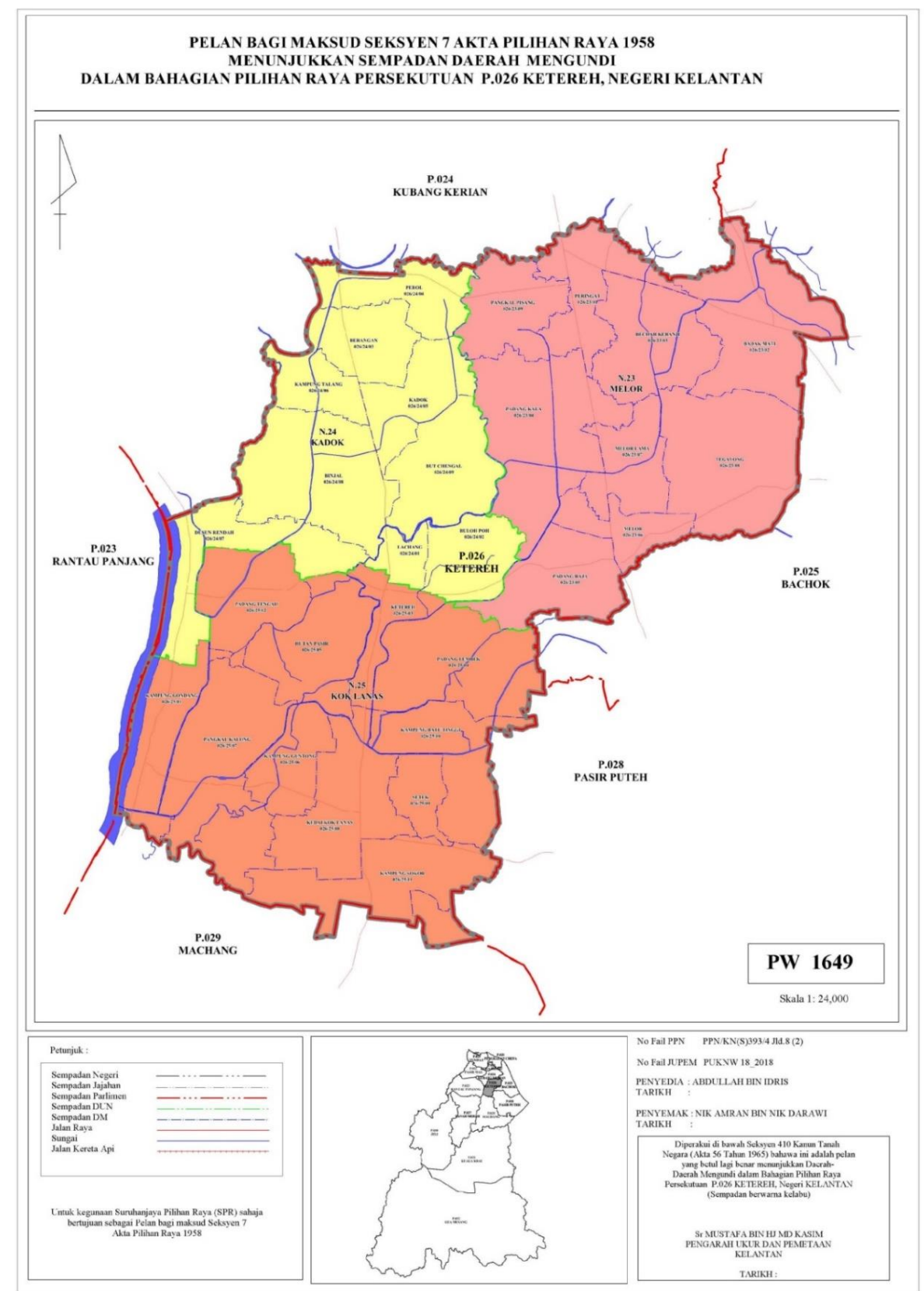

Sumber: SPR (2018)

Rajah 2. Peta kawasan pilihan raya Parlimen Ketereh dan DUN Kadok di Negeri Kelantan

\section{Hasil kajian dan perbincangan}

\section{Impak persempadanan semula bahagian pilihan raya}

Berdasarkan kepada kajian yang dijalankan terhadap urusan persempadanan semula bahagian pilihan raya 2018 di kawasan DUN Kadok dan DUN Salor, telah memberi impak yang besar kepada sistem pilihan raya terutamanya pelaksanaan prinsip-prinsip persempadanan yang perlu diambilkira dalam menjalankan urusan persempadanan di kedua-dua kawasan kajian. Impak persempadanan semula dalam kajian ini dibahagikan kepada 4 aspek utama iaitu; terdapatnya perubahan kedudukan daerah mengundi dan lokaliti dalam kawasan bahagian pilihan raya, perubahan bilangan pemilih, peningkatan dalam urusan bantahan ke atas daftar pemilih dan 
kesan dalam keputusan pilihan raya. Persempadanan ini juga jelas meninggalkan kesan seperti mana yang telah diharapkan oleh parti pemerintah bagi mencapai hasrat dan perluasan kuasa geopolitik pada PRU ke-14.

a. Perubahan kedudukan Daerah Mengundi dan Lokaliti dalam kawasan bahagian pilihan raya

Persempadanan baru yang melibatkan kedua-dua DUN ini telah menyebabkan kedudukan daerah mengundi dan lokaliti berubah. Perubahan ini bukan sahaja memberi kesan kepada wakil rakyat yang dipilih, malah kesan kepada Pegawai Pengurus Pilihan raya tatkala menguruskan sesuatu pilihan raya. Setelah persempadanan baru yang telah diluluskan oleh SPR, dua daerah mengundi dari DUN Melor dimasukkan ke dalam DUN Kadok menjadikan jumlah daerah mengundi di bawah DUN Kadok meningkat kepada 10 daerah mengundi. Dalam usaha untuk mengimbangi jumlah pemilih di DUN Kadok, SPR telah mengeluarkan 3 daerah mengundi dari DUN Kadok iaitu kawasan Kampong Kor, Beta Hulu dan Kedai Piah ke dalam kawasan DUN Salor di bawah Parlimen Kubang Kerian. Perubahan kedudukan ini menjadikan keluasan serta jumlah pemilih di kedua-dua kawasan berubah dan tidak seimbang. Di samping itu juga, perubahan ini menyebabkan timbulnya kekeliruan di peringkat wakil rakyat untuk menyelesaikan isu dan permasalahan rakyat yang timbul kerana kedua-dua kawasan tersebut adalah dibawah kuasa pentadbiran/pihak berkuasa tempatan yang berbeza. Kesulitan ini juga timbul apabila berlakunya pilihan raya, Pegawai Pengurus di kedua-dua parlimen terpaksa berurusan dengan dua pihak berkuasa tempatan yang berbeza bagi satu kawasan pilihan raya. Dapatan ini selari dengan kajian oleh Junaidi et al. (2012a dan 2012b) menjelaskan bahawa persempadanan semula bahagian pilihan raya 2003 menghasilkan perubahan lokasi dan pertambahan serta pengurangan daerah mengundi, pertambahan kerusi DUN.

\section{b. Perubahan bilangan pemilih}

Impak dari persempadanan semula kali ke-6 ini menyebabkan berlakunya pertambahan dan pengurangan bilangan pemilih yang berdaftar di kedua-dua kawasan pilihan raya. Perubahan ini melibatkan di beberapa daerah mengundi yang terkesan persempadanan. Berdasarkan kepada buku Daftar Pemilih yang digunakan untuk PRU ke-13, jumlah pemilih yang berdaftar di DUN Kadok dan DUN Salor ialah masing-masing seramai 17,107 orang dan 20,056 orang. Sehinggalah selesainya proses persempadanan dan diwartakan, jumlah pemilih di kedua-dua kawasan menunjukkan penambahan dan pengurangan yang tidak sekata dan seimbang. Merujuk kepada data yang dikeluarkan, terdapat penambahan pemilih di DUN Kadok seramai 2,153 orang pemilih menjadikan jumlah keseluruhan pemilih berdaftar di DUN Kadok seramai 21,876 orang. Penambahan ini disebabkan kemasukan dua daerah mengundi dari DUN Melor ke DUN Kadok. Bagi mengimbangi jumlah pemilih di DUN Kadok supaya dilihat hampir sama dan seimbang, 3 daerah mengundi dari DUN Kadok iaitu Kampong Kor $(1,726)$, Beta Hulu $(1,663)$ dan Kedai Piah $(1,882)$ yang melibatkan jumlah pemilih seramai 5,271 dikeluarkan dan dimasukkan ke kawasan DUN Salor. Secara keseluruhan, selepas proses persempadanan, jumlah pemilih yang diwartakan bagi DUN Kadok ialah 16,583 orang pemilih jauh lebih rendah jika dibandingkan pada PRU ke-13.

Perkara yang sama juga berlaku pada kawasan kajian di DUN Salor yang menyaksikan pertambahan jumlah pemilih yang tinggi selepas kemasukan beberapa daerah mengundi dari DUN Kadok. Daftar pemilih yang dikeluarkan oleh SPR dan diwartakan untuk PRU ke-13 menunjukkan jumlah pemilih di DUN Salor adalah seramai 20,056. Selepas berlakunya persempadanan, DUN Salor menerima kemasukan 3 daerah mengundi dari DUN Kadok seramai 5,271 orang menjadikan jumlah pemilih keseluruhan adalah 27,164 orang pemilih seperti mana yang diwartakan untuk PRU-14. Oleh itu, masalah ini dapat diatasi dengan hasil 
kajian Flaherty \& Crumplin (1992) yang menjelaskan bahawa kepadatan dan perubahan sempadan bahagian pilihan raya boleh dibuat dengan baik dan adil berdasarkan pengukuran alternatif yang melibatkan kajian dan kerjasama pihak berkuasa tempatan dan suruhan jaya pilihan raya di sesebuah negara.

\section{c. Peningkatan jumlah bantahan ke atas Daftar Pemilih}

Urusan persempadanan memberi kesan menyeluruh bukan hanya dalam proses pilihan raya, malah pengurusan daftar pemilih yang akan diwartakan sama ada semasa tempoh pameran, mahupun pewartaan. Pada kebiasaannya, selaras dengan perkara 119, Perlembagaan Persekutuan (2016), mana-mana pemilih yang telah mencapai umur 21 tahun, dan bermastautin di dalam sesuatu bahagian pilihan raya, layak untuk mendaftar sebagai pemilih pada bila-bila masa. SPR selaku badan yang diberi mandat menguruskan pendaftaran pemilih akan menyediakan senarai pemilih tambahan setiap 3 bulan yang merangkumi pemilih baru dan pemilih yang bertukar alamat. Rang Daftar Pemilih Tambahan (RPDT) yang lengkap akan dipamerkan dimana-mana tempat pameran yang diwartakan bagi tujuan semakan orang ramai dalam tempoh 14 hari. Dalam tempoh tersebut, sepertimana yang diperuntukkan dibawah seksyen 15(1) Peraturan-Peraturan Pilihan Raya (Pendaftaran Pemilih) 2002, mana-mana orang yang namanya ada dalam daftar pemilih induk bagi kawasan pendaftarannya boleh membantah kemasukan namanya atau nama mana-mana orang lain dalam RPDT.

Bagi kes di DUN Kadok, setelah SPR menjalankan urusan sisatan awam ke atas syor kedua persempadan yang melibatkan 3 daerah mengundi iaitu, Kampong Kor, Beta Hulu dan Kedai Piah yang dikeluarkan dari DUN Kadok, terdapat pemilih yang merupakan penyokong tegar sesuatu parti membuat pertukaran tempat mengundi dengan menggunakan mana-mana alamat dalam DUN Kadok selain daripada 3 daerah tersebut, bagi memastikan nama mereka terus kekal dalam DUN Kadok serta memastikan kemenangan parti mereka. Ini menyebabkan wujudnya bantahan ke atas nama-nama mereka oleh mana-mana orang yang pada dasarnya telah mengetahui penama-penama yang dibantah tersebut telah terkeluar dari DUN Kadok. Kelompongan dalam proses pertukaran alamat pada kad pengenalan, dan pertukaran alamat tempat mengundi pada hakikatnya telah memberi peluang kepada individu-individu yang berkepentingan dalam parti politik dan penyokong tegar sesuatu parti untuk memindahkan pemilih-pemilih yang terkesan dengan proses persempadanan ke tempat asal. Berdasarkan kepada rekod bantahan bagi suku 3/2017 yang dikeluarkan oleh SPR, jumlah bantahan bagi Parlimen Ketereh ialah seramai 2,317 orang. Masalah ini dapat diatasi dengan kajian oleh Fryer \& Holden (2011) menjelaskan bahawa pengukuran kepadatan sesuatu kawasan pilihan raya adalah berdasarkan kepada tiga petunjuk iaitu demografi pengundi, pembahagian kluster yang efisien, skala bervarian, kepadatan penduduk dan jumlah daerah pengundian yang ada di sesuatu kawasan pilihan raya.

\section{d. Kesan terhadap keputusan pilihan raya}

Kelantan merupakan kubu kuat PAS pada setiap kali pilihan raya. PAS telah berjaya memerintah di negeri Kelantan semenjak PRU ke-10. Di negeri Kelantan, majoriti penduduk adalah bangsa Melayu yang beragama Islam, maka tidak hairanlah hanya dua parti sahaja iaitu Barisan Nasional (BN) dan Parti Islam Se-Malaysia (PAS) yang sentiasa bertanding dalam pilihan raya parti. Berdasarkan kepada rekod kemenangan PAS pada PRU ke-13, terdapat beberapa bahagian pilihan raya dan DUN yang telah dimenangi oleh BN. Jika dirujuk proses persempadanan di Kelantan yang dilakukan pada tahun 2003, terdapat pertambahan sokongan pengundi terhadap BN. Walau bagaimanapun, bagi DUN Kadok dan DUN Salor, PAS sentiasa memenangi kerusi tersebut pada PRU ke-13 dengan jumlah majoriti masing-masing 3,683 undi 
dan 3,097 undi. Berbeza dengan keputusan di peringkat Parlimen Kubang Kerian dan Ketereh. Di Parlimen Ketereh, BN telah memenangi kerusi parlimen dengan majoriti yang kecil iaitu 974 undi sahaja berbanding di parlimen Kubang Kerian yang dimenangi oleh PAS dengan majoriti 16,741 undi.

Urusan persempadanan 2018 yang dijalankan oleh SPR pada kali ini seolah-olah untuk mengekalkan survival politik BN di parlimen Ketereh. Hal ini jelas ditunjukkan dengan mengeluarkan beberapa daerah mengundi ke Parlimen Kubang Kerian yang dominan terhadap PAS dalam usaha untuk mengurangkan pengaruh dan undi terhadap PAS di Parlimen Ketereh. Pada dasarnya agak sukar untuk BN memenangi kawasan pilihan raya Kubang Kerian dengan majoriti yang besar. Kesannya, pada PRU ke-14, BN telah mencatatkan kemenangan di Parlimen Ketereh dengan majoriti buat julung kalinya mencecah 4,626 undi. Dapatan ini selari dengan hasil kajian oleh Rosmadi (2006 \& 2015) \& Rosmadi et al. (2013) mengaitkan proses persempadanan berbentuk gerimander yang dilakukan oleh SPR yang telah memberi kelebihan kepada parti pemerintah (BN) di DUN Kedah.

Ini jelas menunjukkan proses persempadanan ini telah berjaya memecahkan dominasi PAS dalam kawasan DUN Kadok dengan memberi kelebihan kepada BN untuk memenangi kerusi Parlimen Ketereh. Kesan daripada persempadanan ini juga jelas menunjukkan prinsip 'one vote, one value tidak terpakai bagi pemilih-pemilih yang dikeluarkan ke DUN Salor. Dapatan kajian ini selaras dengan kajian oleh Norelfaedyla (2005) yang menjelaskan bahawa persempadanan semula bahagian pilihan raya telah menghasilkan banyak perubahan kepada pola pengundian.

\section{Pola pengundian}

Melalui perkembangan semasa, kemajuan dalam dunia digital dan kemudahan masyarakat untuk mengakses maklumat-maklumat memberi kesan kepada sesebuah badan pilihan raya dalam memastikan urusan persempadanan lebih telus dan demokratik. Seperti yang dibincangkan sebelum ini, elemen persempadanan berkait rapat dalam sistem pilihan raya terutamanya berkenaan pengurusan daftar pemilih dan penjalanan pilihan raya. Secara keseluruhannya, persempadanan yang dijalankan oleh SPR di DUN Kadok dan DUN Salor mempunyai matlamat tersendiri dalam mengekalkan kuasa geopolitik BN terutamanya di Parlimen Ketereh dengan cara mengurangkan dominasi penyokong PAS di beberapa daerah mengundi. Kesan persempadanan ini juga secara tidak langsung memberi impak yang besar terhadap pola pengundian. Pola pengundian ini merujuk kepada corak pengundian di sesuatu kawasan yang mana ianya berkait rapat dengan tingkah laku pengundi/pemilih dalam pilihanraya. Tingkah laku pengundi di sesuatu kawasan banyak dipengaruhi dengan pelbagai faktor. Faktor ini juga bergantung dengan kawalan sosial yang dilakukan sama ada oleh kerajaan memerintah, SPR dalam melaksanakan persempadanan semula atau sesebuah parti politik.

Secara prinsipnya, pemecahan 3 daerah mengundi yang dikeluarkan dari DUN Kadok telah mewujudkan ketegangan hubungan antara masyarakat setempat. Ini kerana wujudnya ketaksuban dengan ideologi-ideologi parti politik yang dibawa. Jika dibuat perbandingan, DUN Kadok dan Salor merupakan kawasan yang dikategorikan sebagai kawasan perumahan kampung. Dari segi ekonomi, masyarakat di kawasan tersebut adalah peniaga dan ada sebilangannya mendapat bantuan daripada kerajaan. Oleh yang demikian, bilamana terdapat daerah-daerah mengundi yang sepatutnya dibawah pihak berkuasa Majlis Daerah Ketereh, urusan pentadbiran bagi pemilih-pemilih yang terkesan akan berubah dan perlu kepada pihak berkuasa yang lain.

Persempadanan ini juga telah memberi kesan kepada pemilih-pemilih untuk menunaikan tanggungjawab pada hari pilihan raya disebabkan kesukaran untuk untuk akses ke 
pusat mengundi tersebut. Ini menyebabkan jumlah peratusan keluar mengundi menurun jika dibandingkan pada PRU ke-13. Hal yang sama tidak terkecuali pada wakil-wakil rakyat yang dipilih untuk menunaikan tanggungjawab yang diamanahkan apabila terpaksa mendapatkan pandangan dan bantuan dari dua pihak berkuasa tempatan yang berbeza.

Berdasarkan kepada kaedah, prinsip dan konsep pelaksanaan urusan persempadanan pilihan raya yang dilaksanakan oleh SPR pada kali ini selari dengan beberapa kajian seperti Ong (2005) yang menyatakan bahawa, persempadanan yang dilaksanakan oleh pemerintah semestinya akan memberi kelebihan kepada parti pemerintah. Dapatan kajian ini juga selari dengan dapatan kajian Sothi (1992) menghujahkan bahawa parti politik yang mengemudi sesuatu kerajaan dapat menetapkan persempadanan semula kawasan pilihan raya memberi kelebihan kepada parti tersebut dari segi peningkatan kerusi pilihan raya mahupun kewujudan kawasan pilihan raya yang boleh memberi kelebihan kepada parti politik tersebut. Sama ada ianya sengaja atau tidak sengaja dilakukan oleh SPR, pokok pangkalnya SPR selaku badan yang dilantik perlu lebih telus dan mengambilkira prinsip-prinsip persempadanan sepertimana yang terkandung dalam Perlembagaan Persekutuan.

\section{Kesimpulan}

Sebagai kesimpulannya, persempadanan semula bahagian-bahagian pilihan raya 2018 di kawasan DUN Kadok dan DUN Salor memberikan 4 implikasi iaitu pertama terdapatnya perubahan kedudukan daerah mengundi dan lokaliti dalam kawasan bahagian pilihan raya; kedua, perubahan bilangan pemilih; ketiga, peningkatan dalam urusan bantahan ke atas daftar pemilih; dan keempat, kesan dalam keputusan pilihan raya yang mana ianya mempengaruhi keputusan pilihan raya dan juga peratusan pengundi yang keluar mengundi pada PRU ke-14. Persempadanan ini telah memberi kelebihan kepada parti pemerintah berbanding parti PAS yang dominan di Kelantan. Sebagai contoh BN pada PRU ke-13 di Parlimen Ketereh telah memenangi kerusi Parlimen dengan majoriti 974 undi. Pada PRU ke-14, BN berjaya mengekalkan kerusi parlimen dengan majoriti lebih tinggi iaitu 4,626 undi. Impak persempadanan ini banyak memberi kelebihan kepada parti yang ingin meluaskan kuasa geopolitik dan dalam masa yang sama, peratusan pemilih yang keluar mengundi berkurangan kerana terdapatnya kesukaran kepada pemilih untuk melaksanakan tanggungjawab.

\section{Rujukan}

Brown, G. K. (2005). Playing the (non) ethnic card: The electoral system and the ethnic voting patterns in Malaysia. Ethnopolitics, 4(4), 429-445.

Ding Chin Wei, \& Junaidi Awang Besar. (2018). Peranan Strategik Persempadanan Semula Bahagian Pilihan Raya 2016-2017 Menuju Pilihan Raya Umum Ke-14 di Kawasan Parlimen (P137) Bukit Katil, Melaka. Jurnal Wacana Sarjana, 2(3), 1-22.

Fadilah Sarbi. (2015). Konstruk persempadanan etnik dalam pilihan raya: Kajian kes etnik Kadazandusun di Sabah. MANU, 22, 81-105.

Flaherty, M. S., \& Crumplin, W. W. (1992). Compactness and electoral boundary adjustment: An assessment of alternative measures. Canadian Geographer/Le Géographe Canadien, $36(2), 159-171$.

Fryer Jr., R.G. \& Holden, R.. (2011). Measuring the Compactness of Political Districting Plans. The Journal of Law \& Economics. 54(3, August 2011): 493-535.

Glassner, M.I. (1993). Political Geography. New York: John Wiley. 
Hazeeq Hashim. (2015). Pengundi menggelembung siapa untung, siapa rugi?. Dewan Masyarakat. Bil 1/2015.

Ismail Kassim. (1979). Race, Politics and Moderation: A Study of the Malaysian Electoral Process. Singapore: Times Books International.

Junaidi Awang Besar, Mohd Faidz Mohd Zain, \& Novel Lyndon. (2015). Impak sosio-ekonomi dan politik persempadanan semula bahagian pilihan raya Negeri Sarawak. GeografiaMalaysia Journal of Society and Space, 8(7), 1-12.

Junaidi Awang Besar, Mohd Fuad Mat Jali, Rosmadi Fauzi, Amer Saifude Ghazali. (2012a). Pengaruh gerrymandering terhadap pola pengundian di kawasan dewan undangan negeri (DUN) Kajang dan Bangi, Malaysia. Geografia-Malaysia Journal of Society and Space, $8(7), 1-12$.

Junaidi Awang Besar, Mohd Fuad Mat Jali, Rosmadi Fauzi, \& Amer Saifude Ghazali. (2012b). Persempadanan semula kawasan pilihan raya 2003 dan impaknya kepada pilihan raya umum (PRU) 2008 di kawasan dewan undangan negeri (DUN) Kajang dan Bangi, Selangor. e-Bangi: Journal of Social Sciences and Humanities, 7(2), 200-224.

Junaidi Awang Besar, Mazlan Ali, Rosmadi Fauzi, Mohd Nor Shahizan Ali, Handika Wira Mohd Fauzir \& Mohd Syukri Zainuddin. (2017a). Kajian impak persempadanan semula bahagian pilihan raya 2016 di Kawasan Parlimen Serdang dan Hulu Langat Dengan menggunakan pendekatan pemetaan Geographic Information Systems (GIS). International Seminar On Islam, Culture And Heritage: Socio-Political And Economic Issues (ISICH 17). Universiti Utara Malaysia, Sintok, Kedah. Hosted and organized by: School of Languages, Civilisation and Philosophy, Collage of Art and Science, Universiti Utara Malaysia. 30-31 October.

Junaidi Awang Besar, Handika Wira Mohd Fauzir, Mohd Rodzi Abd Razak, \& Ahmad Rizal Mohd Yusof. (2017b). Pandangan Terhadap Perubahan Persempadanan Bahagian Pilihan Raya di Kawasan Parlimen Hulu Langat dan Serdang, Selangor. Geografi, 5(3) Special Issue, 95-111.

JUPEM. (2018). Pelan Pewartaan Bahagian Pilihan Raya Negeri Kelantan. Kota Bharu: JUPEM.

Leib, J., \& Quinton, N. (2016). On the Shores of the "Moribund Backwater"?: Trends in Electoral Geography Research Since 1990. In Warf, B., \& Leib, J. Revitilizing Electoral Geography. New York: Routledge.

Lim Hong Hai. (2003). The delineation of peninsular electoral constituencies: Amplifying Malay and UMNO power. In Francis Loh Kok Wah, \& Johan Saravanamuttu. New Politics in Malaysia. Singapore: Institute of Southeast ASIAN Studies.

Lunday, B. J. (2014). A metric to identify gerrymandering. International Journal of Society Systems Science. 6(3), 285-304.

Norelfaedyla Fadilan. (2005). Kesan persempadanan kawasan pilihan raya 2003 terhadap pilihan raya 2004: Satu kajian kes di DUN Kajang dan DUN Bangi. Latihan Ilmiah. Program Sains Politik, Pusat Pengajian Sejarah, Politik dan Strategi, Fakulti Sains Sosial dan Kemanusiaan, Universiti Kebangsaan Malaysia.

Ong Kian Ming. (2005). Electoral delimitation: A case study of Kedah. In. Mavis Puthucheary \& Norani Othman. Election and Democracy in Malaysia. Bangi: Penerbit Universiti Kebangsaan Malaysia.

Perlembagaan Persekutuan. (2016). Perkara 113. Cetakan semula 2016. Kuala Lumpur: Percetakan Nasional Berhad.

Rosmadi Fauzi. (2006). Geografi politik, pilihan raya dan aplikasi sistem maklumat geografi (GIS) di Malaysia. Jati. 11, 157-177. 
Rosmadi Fauzi. (2015). Isu, cabaran dan prospek aplikasi dan perlaksanaan sistem maklumat geografi di Malaysia: Satu pengamatan. Geografia-Malaysian Journal of Society and Space, 11(2), 118-127.

Rosmadi Fauzi, Mohammad Redzuan Othman, Amer Saifude Ghazali, Zulkanain Abdul Rahman, \& Muhamad Hafiz Abdul Halim. (2013a). Persempadanan semula dan gerimander dalam pilihan raya: Satu pengukuran menggunakan sistem maklumat geografi di DUN Kedah. Geografia-Malaysian Journal of Society and Space, 9(4), 150161.

Sezali Md Darit. (2013). Tahap amalan gerimander dalam persempadanan bahagian pilihan raya: Kes persempadanan Dewan Undangan Negeri Pulau Pinang. Tesis PhD. Program Geografi, Pusat Pengajian Sosial, Pembangunan dan Persekitaran, Fakulti Sains Sosial dan Kemanusiaan, Universiti Kebangsaan Malaysia, Bangi, Selangor.

Sothi Rachagan. (1992). Constituency delimitation in Malaysia: A geographical interpretation. In Voon Phin Keong \& Tunku Shamsul Bahrin. The view from within: Geographical essays on Malaysia and Southeast Asia. Department of Geography, Kuala Lumpur: University of Malaya. 383-411.

SPR. (2003). Laporan Suruhanjaya Pilihan Raya Mengenai Kajian Semula Persempadanan Bahagian-Bahagian Pilihan Raya Parlimen Dan Negeri Bagi Negeri-Negeri Tanah Melayu. (Jilid 1-Syor). Putrajaya: Suruhanjaya Pilihan Raya.

SPR. (2018a). Laporan Kajian Semula Persempadanan Mengenai Syor-Syor yang Dicadangkan bagi Bahagian-Bahagian Pilihan Raya Persekutuan Dan Negeri di dalam Negeri-Negeri Tanah Melayu Kali Keenam Tahun 2018. (Jilid 1). Putrajaya: Suruhanjaya Pilihan Raya.

SPR. (2018b). Buku Daftar Pemilih Suku 2,3,4 tahun 2018. Putrajaya: Suruhanjaya Pilihan Raya.

SUARAM. (2013). Malaysia Human Rights Report 2013: Civil and Political Rights. Petaling Jaya: Suara Inisiatif Sdn. Bhd.

Syed Azman Syed Ahmad Nawawi. (2003). Suruhanjaya Pilihanraya (SPR) Khianati Amalan Demokrasi Berparlimen?. Shah Alam: Angkatan Edaran Ent. Sdn Bhd.

Taylor, P. J. (1973). A new shape measure for evaluating electoral district patterns. The American Political Science Review, 67(3), 947-950.

Wan Mazlina Wan Jama, Rosmadi Fauzi, \& Amer Saifude Ghazali. (2017). Pengukuran elemen ruangan dalam mempengaruhi persempadanan semula pilihan raya di Parlimen Selangor. Persidangan Kebangsaan Geografi dan Alam Sekitar Kali Ke-6, 2017 (PKGAS 2017). Anjuran Jabatan Geografi Dan Alam Sekitar, Fakulti Sains Kemanusiaan, Universiti Pendidikan Sultan Idris, Tanjong Malim, Perak. Di Dewan Konvensyen E-Learning, Kampus Sultan Abdul Jalil Shah, Universiti Pendidikan Sultan Idris, Tanjong Malim, Perak. 26 \& 27 September.

Zin Mahmud. (2016). Demokrasi dan persempadanan semula yang adil. Dewan Masyarakat. Bil 11/2016.

Zulkifli Sulong. (2013). Gerrymandering percaturan licik. Diperoleh daripada http://shazrinmraz.blogspot.com/2013/03/gerrymandering-percaturan-licik.html. 